\title{
2017-2018 Assisted Reproduction Cost Analysis Performance Indexes: Lombardy County Case Study
}

\author{
Paolo Emanuele Levi-Setti ${ }^{1,2 *}$, Andrea Busnelli ${ }^{1,2}$, Annalisa Bodina ${ }^{3}$, Roberto De Luca ${ }^{4}$ \\ and Giulia Scaravelli ${ }^{4}$ \\ 'Department of Biomedical Sciences, Humanitas University, Milan, Italy, ${ }^{2}$ Division of Gynecology and Reproductive \\ Medicine, Department of Gynaecology, Fertility Center, IRCCS Humanitas Research Hospital, Milan, Italy, ${ }^{3}$ Direzione \\ Generale Welfare, Regione Lombardia, Milan, Italy, ${ }^{4}$ Assisted Reproduction Techniques Italian National Register, National \\ Centre for Diseases, Prevention and Health Promotion, National Health Institute, Rome, Italy
}

OPEN ACCESS

Edited by:

Shevach Friedler,

Barzilai Medical Center, Israel

Reviewed by: loannis Sfontouris,

Mitera Hospital, Greece

Talya Shaulov,

University of Montreal Hospital Centre

(CRCHUM), Canada

*Correspondence:

Paolo Emanuele Levi-Setti paolo.levi_setti@humanitas.it

Specialty section:

This article was submitted to Assisted Reproduction,

a section of the journal

Frontiers in Reproductive Health

Received: 12 May 2021

Accepted: 19 July 2021

Published: 12 August 2021

Citation:

Levi-Setti PE, Busnelli A, Bodina A, De Luca R and Scaravelli G (2021) 2017-2018 Assisted Reproduction Cost Analysis Performance Indexes: Lombardy County Case Study. Front. Reprod. Health 3:693715. doi: 10.3389/frph.2021.693715
Objective: The aim of the present study was to analyze the IVF success rates and the economic cost per delivery in all the public funded IVF Units in Lombardy in the 2017-2018 period and to assess any significant difference in ART outcomes among the enrolled centers.

Methods: Analysis of costs for the 2017 and 2018 fresh transfer delivery rate (DR) and Cumulative delivery rate (CDR) considering both fresh and frozen cycles were extracted from the ART Italian Registry on oocytes retrievals, fresh and frozen embryos and oocytes embryo transfer performed in 22 Lombardy IVF Units.

Results: In 2017, 29,718 procedures were performed, resulting in 4,543 pregnancies and 3,253 deliveries. In 2018, there were 29,708 procedures, 4,665 pregnancies and 3,348 deliveries. Pregnancies lost to follow up were 5.0\% with a (range of 0-67.68\%) in 2017 and $3.4 \%$ (range of 0-45.1\%) in 2018. The cost reimbursement for the cycles were $€ 2,232(\$ 2,611)$ for oocyte retrieval and $€ 2,194(\$ 2,567)$ for embryo transfer, excluding ovarian stimulation therapy and luteal phase support. 19.33 (5.80). The DR was 13.23 $\pm 5.69 \%$ (range 2.86-29.11\%) in 2017 and $19.33 \pm 5.80 \%$ in 2018 (range 11.82-34.98 $\%$ ) and the CDR was $19.86 \pm 9.38 \%$ (range 4.43-37.88\%) in 2017 and $21.32 \pm 8.84 \%$ (range 4.24-37.11\%). The mean multiple pregnancy delivery rate (MDR) was $11.08 \pm$ $5.55 \%$ (range $0.00-22.73 \%$ ) in 2017 and $10.41 \pm 4.99 \%$ (range 1.33-22.22\%) in 2018. The mean CDR cost in euros was 26,227 $\pm 14,737$ in 2017 and 25,018 $\pm 16,039$ in 2018. The mean CDR cost among centers was 12,480 to 76,725 in 2017 and 12,973 to 86,203 in 2018.

Conclusions: Our findings show impressive differences in the DR and CDR among centers and the importance of cryopreservation in patients' safety and economic cost reduction suggesting the formulation of specific KPI's (Key performance indexes) and minimal performance indexes (PI) as a basis for the allocation of public or insurance resources. In particular, the reduction of multiple pregnancy rates costs, may lead to a more widespread use of ART even in lower resources countries.

Keywords: ART performance, cumulative delivery rate, cost-analysis, public reimbursement, freeze importance 


\section{KEY MESSAGE}

2017-2018 all Italian, Lombardy County public funded IVF centers cost analysis performance indexes show an impressive variability in cumulative delivery rates, not justified by population treated variables.

\section{INTRODUCTION}

The aim of the present study was to analyze the IVF success rates and the economic cost per delivery in all the public funded IVF Units in Lombardy county in the 2017-2018 period and to assess any significant difference in ART outcomes among the enrolled centers. We also investigated the impact of multiple pregnancy rate (MPR) and lost to follow up pregnancies.

Reimbursement of ART (Assisted Reproduction Techniques) treatments by government-funded programs and third-party payers are not uniform but rather variable. In the latest (2019) global survey of ART practices and policies undertaken by the International Federation of Fertility Societies, only 40 (47\%) of the 85 countries who submitted data on the extent of insurance coverage, reported any type of financial support for ART treatment (1). Such differences influence greatly the number of couples able to access treatment (2-4).

Live birth rates per individual embryo transfer are increased when more than one embryo is transferred, therefore, when patients must pay for treatments as out-of-pocket expenses, or when only a small number of treatment cycles are reimbursed, there is an economic incentive to achieve pregnancy, risking higher multiple pregnancy rates $(5,6)$. A number of studies have shown that the costs of government funding for ART treatments can be theoretically off-set by savings in the health care costs of caring for ART-conceived multiple- birth infants (7).

Comparing results between continents, countries and even regions remains extremely complicated for a variety of reasons, such as huge differences in the cost of treatment and associated differences in access to care, along with differences in the characteristics of the patients being treated (8). Theoretically, national registry data should reflect a more homogeneous background, but data show that the IVF success rate still varies between the different public-funded IVF centers (9). Lintsen et al. investigated whether differences in pregnancy chances among IVF centers remained after controlling for the type of patients treated, reporting differences in 1-year ongoing pregnancy rates between IVF centers even after adjustment for sampling variation and patient mix. According to the authors, future investigations in order to analyze this issue should change perspective and look beyond patients-related factors (9). The importance of big data to support randomized trials and meta-analyses has been recently reinforced $(10,11)$.

In Italy gonadotrophins are supported by National regulation for all public and private practice providing ART cycles as well as for intrauterine inseminations and ovulation induction, up to the age of 45 years. ART cycles, however, are supported with very different reimbursement rates among the 20 Italian counties. The lack of a national regulation of ART, despite legal discussions and proposals to consider ART as an essential medical service requiring assistance, may explain the different county regulations and public vs. private ART funding opportunities. For example, ART cycles performed in 2017 revealed a mean of 32\% (ranging from $86 \%$ in Sicily to $0 \%$ in Sardinia) of cycles performed in private practice arrangements. Lombardy county alone, a region in northern Italy with more than 10 million inhabitants. In its 22 IVF centers, in 2018 were performed $29.8 \%$ of the ovulation inductions $(13,807 / 32,580), 31 \%$ of fresh and frozen procedures $(30,049 / 66,974)$ of the entire country.

Interestingly, $99.0 \%$ of the procedures performed in Lombardy were funded by the public health system, although a small number ( $<1 \%$ were private practice cycles). All the IVF Centers are in hospitals with a gynecological division, often with an Ob-Gyn and emergency department. For all these reason, Lombardy constitutes an ideal case study to compare data on reimbursement and cost per treatment even with the bias of data being reported in aggregate to the National ART Register (12).

\section{MATERIALS AND METHODS}

Data on the number of couples, ovulation induction cycles, fresh and frozen (embryos and oocytes) procedures and outcome of all ART performed in all the 22 Lombardy county public funded IVF Units were extracted from the Assisted Reproductive Technology (ART) Italian National Register (National Center for Diseases, Prevention and Health Promotion, National Health Institute, Rome, Italy) for the years 2017 and 2018. Treatment cycles using donor gametes were excluded.

For each ART Center we calculated: the delivery rate per retrieval, the cumulative delivery rate (CDR) per retrieval (13); the multiple pregnancy rate (MPR); the mean live birth cost (weighted for the number of live births achieved by the single IVF Units); and the lost to follow up rate.

CDR is an estimate (not a true rate, as the data set presented here is cross-sectional) of a cumulative rate, calculated from the fresh ET and those carried out after thawing. The data are presented based on the sum of the fresh, FER (Frozen Embryo Replacement) and FO (Frozen Oocytes) deliveries and the number of aspirations of the same year as the denominator. This parameter was chosen according to the European Register (3) and delivery was defined as the expulsion or extraction of one or more fetuses from the mother after 24 completed weeks of gestational age, modified from International Committee for Monitoring Assisted Reproductive Technology (ICMART) and the World Health Organization (WHO) revised glossary of ART terminology, 2009 (14).

Data about $\mathrm{COH}$ (Controlled Ovarian Hyperstimulation), luteal phase support and endometrial preparation protocols adopted by each IVF Unit were not available. Costs for pharmacological compounds cannot thus be included in the analysis. Costs for the IVF cycles were retrieved from the local Diagnosis-Related Group (DRG) reimbursements (http://www. e-drg.it/drg24/Codici.htm). Specifically, they were as follows: $€ 225$ (US dollar equivalent \$263) for cycle preparation and monitoring (this cost item is reimbursed only for canceled $\mathrm{COH}$ cycles), $€ 2,232(\$ 2,611)$ for oocyte retrieval and $€ 2,194$ 
$(\$ 2,567)$ for embryo transfer. Pregnancy and delivery costs were not included in the cost analysis. For each included Unit, the total cost for the IVF performed procedures was divided by the number of deliveries. Data analysis was performed using the Statistics Package for Social Sciences (SPSS 18). Data was described as mean $\pm \mathrm{SD}$, median (Interquartile range: IQR) or number (\%) and were compared using Student's $t$-test or the "N-1" chi-squared test as appropriate. $P$-values below 0.05 were considered statistically significant.

The number of couples treated and procedures performed by each Center was not included to assure anonymity (15). However, a relation between performing more than 500 cycles was found with oocyte and embryo cryopreservation higher performance (16) and was already published in 2016.

\section{RESULTS}

In 2017 and 2018, Lombardy region counted 22 public funded IVF Clinics which treated 11,577 and 11,221 infertile couples, respectively. Characteristics and outcomes of IVF cycles are reported in Table 1. The mean delivery rate for fresh retrievals (Table 2) was $13.23 \% \pm 5.69$ SD in 2017 (range 2.86-29.11\%) and $19.33 \pm 5.80 \%$ SD (range $11.82-34.98 \%$ ) in 2018 with a mean improvement of $6.10 \% \pm 4.45$ SD (range -1.66 to $15.13 \%$ ).

The CDR per oocyte retrieval was $19.86 \pm 9.38 \%(4.43-$ $37.88 \%)$ in 2017 and $21.32 \% \pm 8.84(4.24-37.11 \%)$ in 2018 (Table 3). Only a small overall average improvement was observed between mean 2017-2018 performance (1.46 $\pm 4.03 \%$ ), with no real differences in best and poor performance centers (Table 4).

The mean multiple pregnancy delivery rate (MDR) in all 22 IVF Centers was $11.08 \pm 5.55 \%$ (range $0.00-22.73 \%$ ) in 2017 and $10.41 \% \pm 4.99$ (range $1.33-22.22 \%$ ), as presented in Table 3.

The cryopreservation incidence (CI) on delivery rate showed a mean of $28.57 \pm 19.61 \%(0-68.25 \%)$ in 2017 and a mean of

TABLE 1 | Characteristics and outcomes of IVF cycles performed in public funded IVF Units in Lombrdy county in 2017 and 2018.

\begin{tabular}{lcc}
\hline Characteristic & $\mathbf{2 0 1 7}$ & $\mathbf{2 0 1 8}$ \\
\hline Public funded IVF Units $(N)$ & 22 & 22 \\
Nr of COH cycles & 15,177 & 14,968 \\
Nr of oocyte retrievals & 13,887 & 13,658 \\
Nr of fresh ETs & 10,190 & 9,770 \\
Nr of FETs & 5,342 & 5,996 \\
Nr of FO cycles & 299 & 284 \\
Rate of women younger than 35 & $28 \pm 8 \%$ & $28 \% \pm 5$ \\
Mean nr of fresh and frozen procedure per IVF Unit & $1.35 \pm 1.25$ & $1.35 \pm 1.28$ \\
Nr of pregnancies achieved & 4,543 & 4,665 \\
Nr of deliveries & 3,253 & 3,348 \\
Nr of live births & 3,590 & 3,665 \\
Pregnancies lost to follow-up & $227(5 \%)$ & $160(3 \%)$ \\
\hline
\end{tabular}

IVF, in vitro fertilization; $\mathrm{COH}$, controlled ovarian hyperstimulation; $E T$, embryo transfer; FET, frozen embryo transfer; FO, frozen oocytes.
$32.19 \pm 20.07 \%(0-66.34 \%)$ in 2018 with a medium increment of $3.62 \pm 11.06 \%$ between the 2 years analyzed (Table 5 ).

The delta percentage difference between the 2 years was $-0.67 \pm 5.09 \%$ with a range from -15.38 to $+10.94 \%$ (Table 5 ).

The mean cost for delivery was 26,227 $\pm 14,737$ (range $12,480-76,725) €$ in 2017 and 25,018 $\pm 16,039$ (range 12,973$86,203) €$ in 2018 (Table 6). Analyzing the 2 years performance, we find a mean cost reduction of $-1,210 \pm 6,327$ Euros, with a maximum 2018 cost reduction of 14,694 Euros and a maximum 2018 higher cost of 9,478 Euros with data detailed for each center in Table 6. The overall cost was 66,843,000 Euros excluding induction therapy, luteal phase support, pregnancy, delivery and neonatal care costs for 3,348 deliveries and 3,665 and 66,865,000 $€$ for 3,590 live babies born in 2017 .

\section{DISCUSSION}

In this study, we show fresh cycle DR, CDR, CI, MDR, and cost for delivery of all public funded Lombardy county IVF centers is extremely different among centers in the same region.

To the best of our knowledge, this is one of the first contributions that investigated the impact of CDR in total costs of ART procedures and how different center policies and performances affects this specific variable.

TABLE 2 | Delivery rate \% for fresh transfer in the 22 IVF centers in the period 2017-2018.

\begin{tabular}{|c|c|c|c|}
\hline \multirow[b]{2}{*}{ ART CENTER } & \multicolumn{3}{|c|}{ Delivery rate fresh cycle $\times$ retrieval $\%$} \\
\hline & 2017 & 2018 & DELTA \\
\hline $\mathrm{C} 1$ & 13.55 & 14.49 & 0.94 \\
\hline $\mathrm{C} 2$ & 21.01 & 19.34 & -1.66 \\
\hline C3 & 17.91 & 23.83 & 5.92 \\
\hline C4 & 13.27 & 15.57 & 2.30 \\
\hline C5 & 8.55 & 13.04 & 4.48 \\
\hline C6 & 14.53 & 23.42 & 8.89 \\
\hline $\mathrm{C} 7$ & 6.94 & 22.08 & 15.13 \\
\hline C8 & 8.82 & 13.08 & 4.25 \\
\hline C9 & 17.18 & 21.72 & 4.54 \\
\hline C10 & 29.11 & 34.98 & 5.87 \\
\hline C11 & 2.86 & 11.82 & 8.95 \\
\hline C12 & 15.84 & 30.88 & 15.03 \\
\hline C13 & 13.53 & 20.93 & 7.40 \\
\hline C14 & 16.30 & 17.83 & 1.53 \\
\hline C15 & 9.47 & 13.49 & 4.02 \\
\hline C16 & 7.69 & 21.41 & 13.71 \\
\hline C17 & 10.87 & 19.08 & 8.21 \\
\hline C18 & 9.42 & 14.48 & 5.06 \\
\hline C19 & 18.99 & 23.49 & 4.51 \\
\hline $\mathrm{C} 20$ & 14.02 & 15.99 & 1.97 \\
\hline $\mathrm{C} 21$ & 12.96 & 16.41 & 3.44 \\
\hline $\mathrm{C} 22$ & 8.26 & 17.86 & 9.60 \\
\hline Mean \pm SD & $13.23(5.69)$ & $19.33(5.80)$ & $6.10(4.45)$ \\
\hline Minimum & 2.86 & 11.82 & -1.66 \\
\hline Maximum & 29.11 & 34.98 & 15.13 \\
\hline
\end{tabular}


TABLE 3 | Cumulative delivery rate (CDR) in all 22 IVF centers in the period 2017-2018.

\begin{tabular}{|c|c|c|c|}
\hline \multirow[b]{2}{*}{ ART CENTER } & \multicolumn{3}{|c|}{ Cumulative Delivery rate $\%$} \\
\hline & 2017 & 2018 & DELTA \\
\hline C1 & 25.81 & 26.57 & 0.76 \\
\hline C2 & 28.06 & 24.35 & -3.71 \\
\hline C3 & 18.54 & 17.50 & -1.04 \\
\hline C4 & 19.44 & 24.85 & 5.41 \\
\hline C5 & 26.95 & 30.69 & 3.75 \\
\hline C6 & 32.40 & 36.08 & 3.67 \\
\hline C7 & 11.11 & 19.48 & 8.37 \\
\hline C8 & 8.82 & 6.92 & -1.90 \\
\hline C9 & 24.95 & 26.71 & 1.76 \\
\hline C10 & 37.67 & 30.80 & -6.87 \\
\hline C11 & 4.43 & 4.24 & -0.18 \\
\hline C12 & 16.83 & 25.81 & 8.97 \\
\hline C13 & 13.91 & 15.12 & 1.21 \\
\hline C14 & 25.30 & 21.02 & -4.29 \\
\hline C15 & 20.33 & 21.63 & 1.29 \\
\hline C16 & 8.31 & 11.01 & 2.70 \\
\hline C17 & 16.21 & 21.97 & 5.76 \\
\hline C18 & 11.23 & 12.46 & 1.23 \\
\hline C19 & 37.88 & 37.11 & -0.77 \\
\hline C20 & 20.56 & 18.33 & -2.23 \\
\hline C21 & 19.91 & 26.17 & 6.26 \\
\hline $\mathrm{C} 22$ & 8.26 & 10.16 & 1.90 \\
\hline Mean \pm SD & $19.86(9.38)$ & $21.32(8.84)$ & $1.46(4.43)$ \\
\hline Minimum & 4.43 & 4.24 & -6.87 \\
\hline Maximum & 37.88 & 37.11 & 8.97 \\
\hline
\end{tabular}

The mean number of pregnancies lost to follow up was lower than $10 \%$, considered in general an acceptable reporting rate level by most ART Registers. However, some centers had a loss to follow up of reported pregnancies as high as $47 \%$, leading to no news about pregnancy outcome and complications as high as nearly $50 \%$ of the obtained pregnancies and probably too confusing self-reported pregnancy rates.

The mean DR for fresh embryo transfers as shown in Table 1, had an important 2017-2018 overall mean improvement from 13.23 to $19.33 \%$ without a higher $2017-2018$ mean multiple pregnancy rate as shown in Tables 1, 2 and although female age is significantly higher in our country than in others and in Lombardy County specifically. Some centers showed significant improvement without a higher multiple rate, but data show an impressive variability among centers not fully justified by any clinical variability in the treated population or by the number of embryos transferred. DR in fresh transfer probably penalize centers where younger more favorable prognosis is always canceled for the risk of hyperstimulation or single embryo transfer is more often performed and benefit centers transferring more than one embryo even in higher risk conditions $(17,18)$. Fresh transfer performance is a poor and rather confusing (19, 20 ) than CDR, since frozen embryos are a yearly growing success
TABLE 4 | Multiple delivery rate (MDR) in all 22 IVF centers in the period 2017-2018.

\begin{tabular}{|c|c|c|c|}
\hline \multirow[b]{2}{*}{ ART CENTER } & \multicolumn{3}{|c|}{ Multiple Delivery rate $\%$} \\
\hline & 2017 & 2018 & DELTA \\
\hline C1 & 3.78 & 1.33 & -2.45 \\
\hline C2 & 14.10 & 10.76 & -3.34 \\
\hline C3 & 15.60 & 12.78 & -2.82 \\
\hline C4 & 10.00 & 2.35 & -7.65 \\
\hline C5 & 3.67 & 6.13 & 2.47 \\
\hline C6 & 0.00 & 10.94 & 10.94 \\
\hline $\mathrm{C} 7$ & 13.51 & 13.46 & -0.05 \\
\hline C8 & 14.29 & 18.18 & 3.90 \\
\hline C9 & 8.83 & 10.48 & 1.65 \\
\hline C10 & 14.06 & 10.99 & -3.07 \\
\hline C11 & 15.00 & 12.50 & -2.50 \\
\hline C12 & 22.73 & 22.22 & -0.51 \\
\hline C13 & 15.91 & 15.22 & -0.69 \\
\hline C14 & 5.45 & 4.81 & -0.65 \\
\hline C15 & 7.59 & 6.06 & -1.53 \\
\hline C16 & 6.90 & 12.20 & 5.30 \\
\hline C17 & 6.49 & 10.87 & 4.38 \\
\hline C18 & 20.51 & 5.13 & -15.38 \\
\hline C19 & 9.54 & 7.91 & -1.62 \\
\hline C20 & 12.24 & 8.11 & -4.14 \\
\hline C21 & 10.42 & 11.84 & 1.43 \\
\hline C22 & 13.21 & 14.71 & 1.50 \\
\hline Mean \pm SD & $11.08(5.55)$ & $10.41(4.99)$ & $-0.67(5.09)$ \\
\hline Minimum & 0.00 & 1.33 & -15.38 \\
\hline Maximum & 22.73 & 22.22 & 10.94 \\
\hline
\end{tabular}

experience and need probably to be dismissed from all reports. MDR, although a reduction in the 2017-2018 period of data extraction was observed, remained as high as $22 \%$ in one IVF center as shown in Table 3.

The last (2016 data) 2020 European Register CDR calculation included data from 38 countries where an overall rate of $29.6 \%$ was reported with a range of $4.10-51.80 \%$. The Italian overall rate was in $201618.60 \%$ (3). Lombardy County 2018 CDR was higher than the Italian overall percentage (21.32 vs. $19.4 \%)$ with a 2017 vs. 2018 overall better performance (+1.46\%). However, differences in single center CDR ranged from 4.24 to $37.11 \%$. Our data strongly support the conclusion that CDR are extremely different not only among different European countries as reported in 2020 by the European Register, but even among the same region of public funded IVF centers, as shown in 2010 by the 1 year pregnancy rate among all the Netherland's public funded clinics (9). Some Lombardy IVF centers performance was in the higher European ranking ( $>35 \%$ CDR), but others had an extremely low and not improving CDR as shown in Table 2.

The benefit taken from additional FER (over the DR from fresh embryo transfers) was $10.5 \%$, with a highest benefit recorded of $26.1 \%$ and the lowest of $0 \%$ according to the European Register (3). 
TABLE 5 | Cryopreservation incidence on cumulative delivery RATE \% in all 22 IVF centers in the period 2017-2018.

\begin{tabular}{|c|c|c|c|}
\hline \multirow[b]{3}{*}{ ART CENTER } & \multicolumn{3}{|c|}{ 2017-2018 Lombardy ART data analysis } \\
\hline & \multicolumn{3}{|c|}{ Crypreservation incidence on delivery rate $\%$} \\
\hline & 2017 & 2018 & DELTA \\
\hline $\mathrm{C} 1$ & 47.50 & 56.2 & 8.73 \\
\hline $\mathrm{C} 2$ & 25.13 & 39.7 & 14.59 \\
\hline C3 & 3.36 & 2.6 & -0.78 \\
\hline C4 & 31.75 & 50.6 & 18.86 \\
\hline C5 & 68.25 & 66.3 & -1.91 \\
\hline C6 & 55.17 & 45.6 & -9.56 \\
\hline $\mathrm{C} 7$ & 37.50 & 13.3 & -24.17 \\
\hline $\mathrm{C} 8$ & 0.00 & 0.0 & 0.00 \\
\hline C9 & 31.15 & 36.5 & 5.33 \\
\hline C10 & 22.73 & 19.8 & -2.97 \\
\hline C11 & 35.29 & 21.4 & -13.87 \\
\hline C12 & 5.88 & 16.1 & 10.19 \\
\hline C13 & 2.70 & 15.4 & 12.68 \\
\hline C14 & 35.58 & 42.4 & 6.85 \\
\hline C15 & 53.42 & 57.0 & 3.56 \\
\hline C16 & 7.41 & 8.3 & 0.93 \\
\hline C17 & 32.95 & 33.7 & 0.71 \\
\hline C18 & 16.13 & 43.2 & 27.11 \\
\hline C19 & 49.88 & 51.7 & 1.80 \\
\hline $\mathrm{C} 20$ & 31.78 & 37.3 & 5.47 \\
\hline $\mathrm{C} 21$ & 34.88 & 49.3 & 14.37 \\
\hline $\mathrm{C} 22$ & 0.00 & 1.7 & 1.72 \\
\hline All (mean) & 28.57 & 32.19 & 3.62 \\
\hline All (SD) & 19.61 & 20.07 & 11.06 \\
\hline ALL (minimum) & 0.00 & 0.00 & -24.17 \\
\hline All (maximum) & 68.25 & 66.34 & 27.11 \\
\hline
\end{tabular}

Lombardy IVF centers 2018 incidence of FER and FO on CDR was higher than the overall reported by European Register (32.19 vs. the $10.5 \%$ ) with a benefit as high as $66.34 \%$.

Italian oocyte utilization is different from other countries, since, even after in 2009, the Constitutional Court removed the prohibition of embryo cryopreservation and the limitations to three oocytes only to be utilized, immediately improving overall results $(21,22)$, all IVF centers decided not to fertilize all the mature oocyte's retrieved, but to cryopreserve oocytes and embryo to reduce the number of stored embryos and the total number of oocytes to be utilized is a decision of each center, even in few cases superior to 12 oocytes. This different policies in oocyte utilization even if FO deliveries are reported, are a bias to make comparison with other countries and made it probably not possible.

We conducted a long analysis to evaluate differences in centers performance influencing the cost for baby born and our conclusions show that the total cost for ART procedure is extremely low in relation of the 2019 total Regional health care budget $(0.34 \%)$ and the mean cost for delivery was probably acceptable for the country with the lower delivery rate and the
TABLE 6 | Cost for the NHS of delivery in all 22 IVF Centers in the period 2017-2018 (conversion Euro to US dollar 1.17).

\begin{tabular}{|c|c|c|c|}
\hline \multirow[b]{2}{*}{ ART CENTER } & \multicolumn{3}{|c|}{ Total cost for delivery (Euros) } \\
\hline & 2017 & 2018 & DELTA \\
\hline C1 & 17,838 & 18,845 & 1,007 \\
\hline C2 & 16,067 & 20,065 & 3,998 \\
\hline C3 & 19,101 & 20,859 & 1,758 \\
\hline C4 & 22,211 & 19,482 & $-2,728$ \\
\hline C5 & 17,876 & 15,543 & $-2,333$ \\
\hline C6 & 16,254 & 12,973 & $-3,282$ \\
\hline $\mathrm{C7}$ & 33,385 & 19,990 & $-13,395$ \\
\hline C8 & 37,607 & 45,614 & 8,006 \\
\hline C9 & 18,145 & 16.104 & -2.041 \\
\hline C10 & 15,356 & 15,356 & 0 \\
\hline C11 & 76,725 & 86,203 & 9,478 \\
\hline C12 & 20,301 & 14,563 & $-5,739$ \\
\hline C13 & 23,114 & 23,772 & 658 \\
\hline C14 & 17,468 & 22,370 & 4,902 \\
\hline C15 & 20,848 & 20,091 & -757 \\
\hline C16 & 47,017 & 32,323 & $-14,694$ \\
\hline C17 & 27,961 & 19,487 & $-8,474$ \\
\hline C18 & 30,404 & 35,192 & 4,788 \\
\hline C19 & 12,480 & 13,134 & 654 \\
\hline C20 & 21,666 & 26,361 & 4,696 \\
\hline C21 & 19,500 & 15,632 & $-3,868$ \\
\hline C22 & 45,679 & 36,430 & $-9,249$ \\
\hline Mean \pm SD & $26,227(14,737)$ & $25,018(16,039)$ & $-1,210(6,327)$ \\
\hline Minimum & 12,480 & 12,973 & $-14,694$ \\
\hline Maximum & 76,725 & 86,203 & 9,478 \\
\hline
\end{tabular}

higher women mean age at delivery in Europe (23). However, enormous difference was found among centers in our results leading to 12,973 Euros (15,158 US dollars) to 86,203 Euros (100,962 US dollars) cost for delivery.

The risk of multiple pregnancy in centers with a greater propensity to cryopreservation is probably associated with the implementation of more elective single embryo transfers (eSET) which is associated with a multiple pregnancy incidence reduction $(24,25)$ and a significant progressive decrease in the risks for the mother related to oocyte retrieval (26) and in the costs of drugs needed to induce ovulation, pregnancy care and interventions required for neonatal complications. Considering the higher costs for both gestation and neonatal care in multiple pregnancies, we speculate that the inclusion of these expense items would further acquire the cost differences per live birth and the observed trend and probably cover the total ART procedure costs (5).

Some limitations of our study should be recognized. First, we took some necessary arbitrary and debatable decisions. We cannot exclude that in our setting these variables could have an influence. The economic analysis deserves a critical evaluation. Interventions with an unfavorable economic profile are usually not supported by public health policies, however, we do not believe that our data can yet be used by the 
public health providers to implement a restriction policy, in relation to couples with poor prognosis. Results from economic analyses are markedly influenced by the basal assumptions and results may differ substantially with the use of different models. Furthermore, a substantial part of IVF associated costs (i.e., pregnancy and neonatal care costs) were not included in the model. Consequently, conclusion applicable to the management of public resources cannot be drawn. The data reported in the present study refer to the 2-year period 2017-2018. These are the most recent data published by the Italian National Center for Diseases, Prevention, and Health Promotion for which the outcomes of all achieved pregnancies are available. We therefore deem that their synthesis could represent the current situation as reliably as possible but, obviously we cannot be sure. Finally, our results are based on the data provided by the 22 Lombardy county public funded IVF Units. This implies that these findings cannot be considered valid for the remaining national and extranational territory. In central and southern Italy, for example, many patients turn to private centers which, for many reasons, cannot be compared to public ones. Looking at Europe, the average number of public IVF Units per inhabitant is significantly lower than in Lombardy with a consequent different distribution of resources. Furthermore, national health care systems are financed by different models of funding (e.g., tax revenue or multi-payer system and municipal or national healthcare funding). More robust prospective evidence from other contexts is thus warranted.

In conclusion our results highly support in a very different setting data published by Lintsen et al. (9) which demonstrated that differences in 1-year ongoing pregnancy rates between public funded IVF centers exist, even after adjustment for sampling variation and patient mix. Our focus on delivery rate was more detailed in understanding the real costs for baby born, than the cited manuscripts. Unfortunately, our reported data in

\section{REFERENCES}

1. International Federation of Fertility Societies. International Federation of Fertility Societies (IFFS), Surveillance 2019: global trends in reproductive policy and practice, 8th Edition. Glob Reprod Health. (2019) 4:29. doi: 10.1097/GRH.0000000000000029

2. De Geyter C, Calhaz-Jorge C, Kupka MS, Wyns C, Mocanu E, Motrenko T, et al. ART in Europe, 2014: results generated from European registries by ESHRE: the European IVF-monitoring Consortium (EIM) for the European Society of Human Reproduction and Embryology (ESHRE). Hum Reprod. (2018) 33:1586-601. doi: 10.1093/humrep/dey242

3. Wyns C, Bergh C, Calhaz-Jorge C, De Geyter C, Kupka MS, Motrenko T, et al. ART in Europe, 2016: results generated from European registries by ESHRE. Hum Reprod Open. (2020) 2020:hoaa032. doi: 10.1093/hropen/hoz044

4. De Geyter C, Calhaz-Jorge C, Kupka MS, Wyns C, Mocanu E, Motrenko T, et al. ART in Europe, 2015: results generated from European registries by ESHRE. Hum Reprod Open. (2020) 2020:hoz038. doi: 10.1093/hropen/hoaa038

5. Chambers G, Keller E, Choi S, Khalaf Y, Crawford S, Botha $\mathrm{W}$, et al. Funding and public reporting strategies for reducing multiple pregnancy from fertility treatment. Fertil Steril. (2020) 1114:715-21. doi: 10.1016/j.fertnstert.2020.08.1405

6. Chambers GM, Hoang VP, Sullivan EA, Chapman MG, Ishihara O, Zegers-Hochschild F, et al. The impact of consumer affordability this publication are retrospective, aggregated data with all the possible bias related to this specific context. We consider our findings as fundamental for the formulation of specific KPI's (Key performance indexes) and minimal performance indexes (PI) (27) as a basis to the allocation of public or insurance resources, leading to a more general spread of ART even in lower resources countries.

\section{DATA AVAILABILITY STATEMENT}

Publicly available datasets were analyzed in this study. This data can be found here: National Institute of Health Italian National Register.

\section{ETHICS STATEMENT}

Ethical review and approval was not required for the study on human participants in accordance with the local legislation and institutional requirements. The patients/participants provided their written informed consent to participate in this study.

\section{AUTHOR CONTRIBUTIONS}

PL-S, GS, and ABu: conception and design. PL-S, ABu, ABo, $\mathrm{RD}$, and GS: data extraction, interpretation, and critical revision of the manuscript. RD: analysis. PL-S: drafting the manuscript. All authors contributed to the article and approved the submitted version.

\section{ACKNOWLEDGMENTS}

The authors thank all the Lombardy ART Centers for providing their data and Pasquale Patrizio, the Yale Fertility Center for the manuscript revision.

on access to assisted reproductive technologies and embryo transfer practices: an international analysis. Fertil Steril. (2014) 101:191-8.e4. doi: 10.1016/j.fertnstert.2013.09.005

7. Chambers GM, Hoang VP, Lee E, Hansen M, Sullivan EA, Bower C, et al. Hospital costs of multiple-birth and singleton-birth children during the first 5 years of life and the role of assisted reproductive technology. JAMA Pediatr. (2014) 168:1045-53. doi: 10.1001/jamapediatrics.2014.1357

8. Fauser BCJM, Boivin J, Barri PN, Tarlatzis BC, Schmidt L, Levy-Toledano R. Beliefs, attitudes and funding of assisted reproductive technology: public perception of over 6,000 respondents from 6 European countries. PLoS One. (2019) 14:e0211150. doi: 10.1371/journal.pone.0211150

9. Lintsen AM, Braat DD, Habbema JD, Kremer JA, Eijkemans MJ. Can differences in IVF success rates between centres be explained by patient characteristics and sample size? Hum Reprod. (2010) 25:110-7. doi: 10.1093/humrep/dep358

10. Venetis C, d'Hooghe T, Barnhart KT, Bossuyt PMM, Mol BWJ. Methodologic considerations in randomized clinical trials in reproductive medicine. Fertil Steril. (2020) 113:1107-12. doi: 10.1016/j.fertnstert.2020.04.038

11. Paulson SS, Scruth E. Legal and ethical concerns of big data: predictive analytics. Clin Nurse Spec. (2017) 31:237-9. doi: 10.1097/NUR.0000000000000315

12. Scaravelli G. Benefit and risk of application of European tissue management regulation in ART. Placenta. (2011) 32(Suppl. 3):S243-7. doi: 10.1016/j.placenta.2011.07.003 
13. Maheshwari A, McLernon D, Bhattacharya S. Cumulative live birth rate: time for a consensus? Hum Reprod. (2015) 30:2703-7. doi: 10.1093/humrep/ $\operatorname{dev} 263$

14. Zegers-Hochschild F, Adamson GD, de Mouzon J, Ishihara O, Mansour $\mathrm{R}$, Nygren $\mathrm{K}$, et al. International Committee for Monitoring Assisted Reproductive Technology (ICMART), and the World Health Organization (WHO) revised glossary of ART terminology, 2009. Fertil Steril. (2009) 92:1520-4. doi: 10.1016/j.fertnstert.2009.09.009

15. Scaravelli G, Levi-Setti PE, Livi C, La Sala G, Ubaldi FM, Greco E, et al. Contribution of cryopreservation to the cumulative live birth rate: a large multicentric cycle-based data analysis from the Italian National Registry. J Assist Reprod Genet. (2019) 36:2287-95. doi: 10.1007/s10815-01901566-y

16. Levi-Setti PE, Patrizio P, Scaravelli G. Evolution of human oocyte cryopreservation: slow freezing versus vitrification. Curr Opin Endocrinol Diabetes Obes. (2016) 23:445-50. doi: 10.1097/MED.00000000000 00289

17. Wei D, Legro RS, Chen ZJ. The cumulative live birth rate after a freezeonly strategy versus a conventional fresh embryo transfer strategy: a call for more level 1 evidence. BMC Med. (2020) 18:12. doi: 10.1186/s12916-019$1479-2$

18. Cutting R. Single embryo transfer for all. Best Pract Res Clin Obstet Gynaecol. (2018) 53:30-7. doi: 10.1016/j.bpobgyn.2018.07.001

19. Shi Y, Sun Y, Hao C, Zhang H, Wei D, Zhang Y, et al. Transfer of fresh versus frozen embryos in ovulatory women. N Engl J Med. (2018) 378:126-36. doi: 10.1056/NEJMoa1705334

20. Roque M, Valle M, Guimarães F, Sampaio M, Geber S. Freeze-all policy: fresh vs. frozen-thawed embryo transfer. Fertil Steril. (2015) 103:1190-3. doi: 10.1016/j.fertnstert.2015.01.045

21. Levi Setti PE, Albani E, Matteo M, Morenghi E, Zannoni E, Baggiani AM, et al. Five years (2004-2009) of a restrictive law-regulating ART in Italy significantly reduced delivery rate: analysis of 10,706 cycles. Hum Reprod. (2013) 28:343-9. doi: 10.1093/humrep/des404

22. Levi Setti PE, Albani E, Cesana A, Novara PV, Zannoni E, Baggiani AM, et al. Italian Constitutional Court modifications of a restrictive assisted reproduction technology law significantly improve pregnancy rate. Hum Reprod. (2011) 26:376-81. doi: 10.1093/humrep/deq342
23. Seke K, Petrovic N, Jeremic V, Vukmirovic J, Kilibarda B, Martic M. Sustainable development and public health: rating European countries. BMC Public Health. (2013) 13:77. doi: 10.1186/1471-2458-13-77

24. Tiitinen A, Halttunen M, Härkki P, Vuoristo P, Hyden-Granskog C. Elective single embryo transfer: the value of cryopreservation. Hum Reprod. (2001) 16:1140-4. doi: 10.1093/humrep/16.6.1140

25. Tiitinen A, Hydén-Granskog C, Gissler M. What is the most relevant standard of success in assisted reproduction?: The value of cryopreservation on cumulative pregnancy rates per single oocyte retrieval should not be forgotten. Hum Reprod. (2004) 19:2439-41. doi: 10.1093/humrep/deh446

26. Levi-Setti PE, Cirillo F, Scolaro V, Morenghi E, Heilbron F, Girardello D, et al. Appraisal of clinical complications after 23,827 oocyte retrievals in a large assisted reproductive technology program. Fertil Steril. (2018) 109:103843.e1. doi: 10.1016/j.fertnstert.2018.02.002

27. Fabozzi G, Cimadomo D, Maggiulli R, Vaiarelli A, Ubaldi FM, Rienzi L. Which key performance indicators are most effective in evaluating and managing an in vitro fertilization laboratory? Fertil Steril. (2020) 114:915.doi: 10.1016/j.fertnstert.2020.04.054

Conflict of Interest: The authors declare that the research was conducted in the absence of any commercial or financial relationships that could be construed as a potential conflict of interest.

Publisher's Note: All claims expressed in this article are solely those of the authors and do not necessarily represent those of their affiliated organizations, or those of the publisher, the editors and the reviewers. Any product that may be evaluated in this article, or claim that may be made by its manufacturer, is not guaranteed or endorsed by the publisher.

Copyright (c) 2021 Levi-Setti, Busnelli, Bodina, De Luca and Scaravelli. This is an open-access article distributed under the terms of the Creative Commons Attribution License (CC BY). The use, distribution or reproduction in other forums is permitted, provided the original author(s) and the copyright owner(s) are credited and that the original publication in this journal is cited, in accordance with accepted academic practice. No use, distribution or reproduction is permitted which does not comply with these terms. 